\title{
COMParison of Byblis 'Goliath' (B. FILIFOlia), BYBLIS 'DAVID' (B. LINIFLORA), AND THEIR PUTATIVE FERTILE HYBRID
}

IRMgaRd And SiegrRied R.H. HaRTMEYeR • Wittlinger Str. 5 • 79576 Weil am Rhein • Germany - www.hartmeyer.de

Keywords: Byblis filifolia, Byblis liniflora, cross pollination, hybrids

Submitted: 6 A ugust 2011, revised 18 September 2011

\section{A bstract}

Seed derived plants from the cultivars, Byblis 'Goliath' (B arnes 2009) and Byblis 'D avid' (Barnes 2010) were cross pollinated. W hile the Byblis 'G oliath' needs buzz-pollination to release pollen, the hybrid between these two taxa develops self-pollinating flowers, like its robust B. liniflora parent. This paper is a study of these cross pollination events and its results.

\section{Introduction}

A strongly branching plant of Byblis filifolia 'Goliath' (Barnes 2009) and the self-pollinating Byblis liniflora 'D avid' (Barnes 2010, similar varieties have been common in German C P-collections since the mid 1980s) were cross pollinated. While the mother plant B. ' $G$ oliath' needs buzzpollination to release pollen, the supposed hybrid (see Figs. 1 and 2) develops self-pollinating, obviously very fecund flowers, like its male ancestor B. 'D avid'. This paper is a comparative study of the three plants.

\section{Settings and experiment}

Both parental plants (P-generation) grow side by side in our tropical greenhouse in Weil am Rhein (Germany). They receive full sunlight (southwestern exposure) and get only de-ionized water. The summer temperatures vary around $24-36^{\circ} \mathrm{C}$ during daytime (winter $=15-26^{\circ} \mathrm{C}$ ) and between $16-24^{\circ} \mathrm{C}$ during nighttimes (winter $=12-15^{\circ} \mathrm{C}$ ). During winter additional $\mathrm{HQI}$-lighting and heating is provided. At the time of pollination no other Byblis species have been present in our collection; therefore any other accidental cross-pollination can be excluded with certainty.

Since the mid 1980s, the small self-pollinating variety of B. liniflora has been part of our collection. The richly produced seeds remain fertile for several years, so it's no problem to keep the cultivation pattern going even over decades. With our conditions, individual plants survived up to two years, but they are annual in the wild, due to seasonal droughts. Without cutting the tip or injuring the stem, during more than 25 years this variety never developed any branches under our growing conditions. The species remains relatively small and rarely exceeds $18-20 \mathrm{~cm}$ height. We produced two time-lapse videos of our plants to demonstrate the leaf-movement by pulvinus (Hartmeyer \& Hartmeyer 2010). 


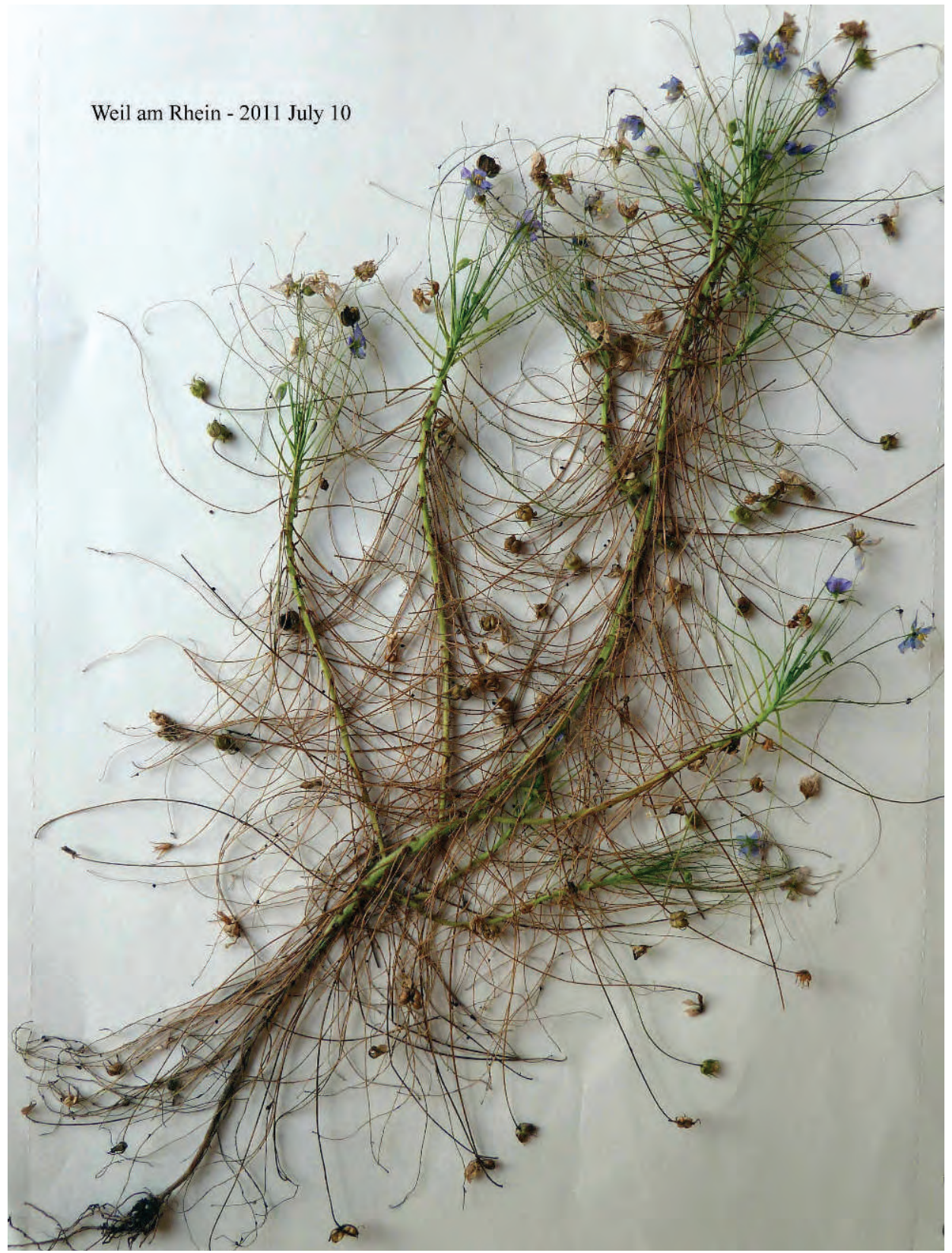

Figure 1: Byblis cf. filifolia $\times$ liniflora dried plant showing branching pattern and general habit. Photo by S. Hartmeyer.

Brian Barnes (Barnes 2010) described a larger growing form of Byblis liniflora, as Byblis 'David' (see Fig. 3) also a self-pollinating plant. The seed for this selected cultivar was obtained from Rareexoticseeds in Canada. 


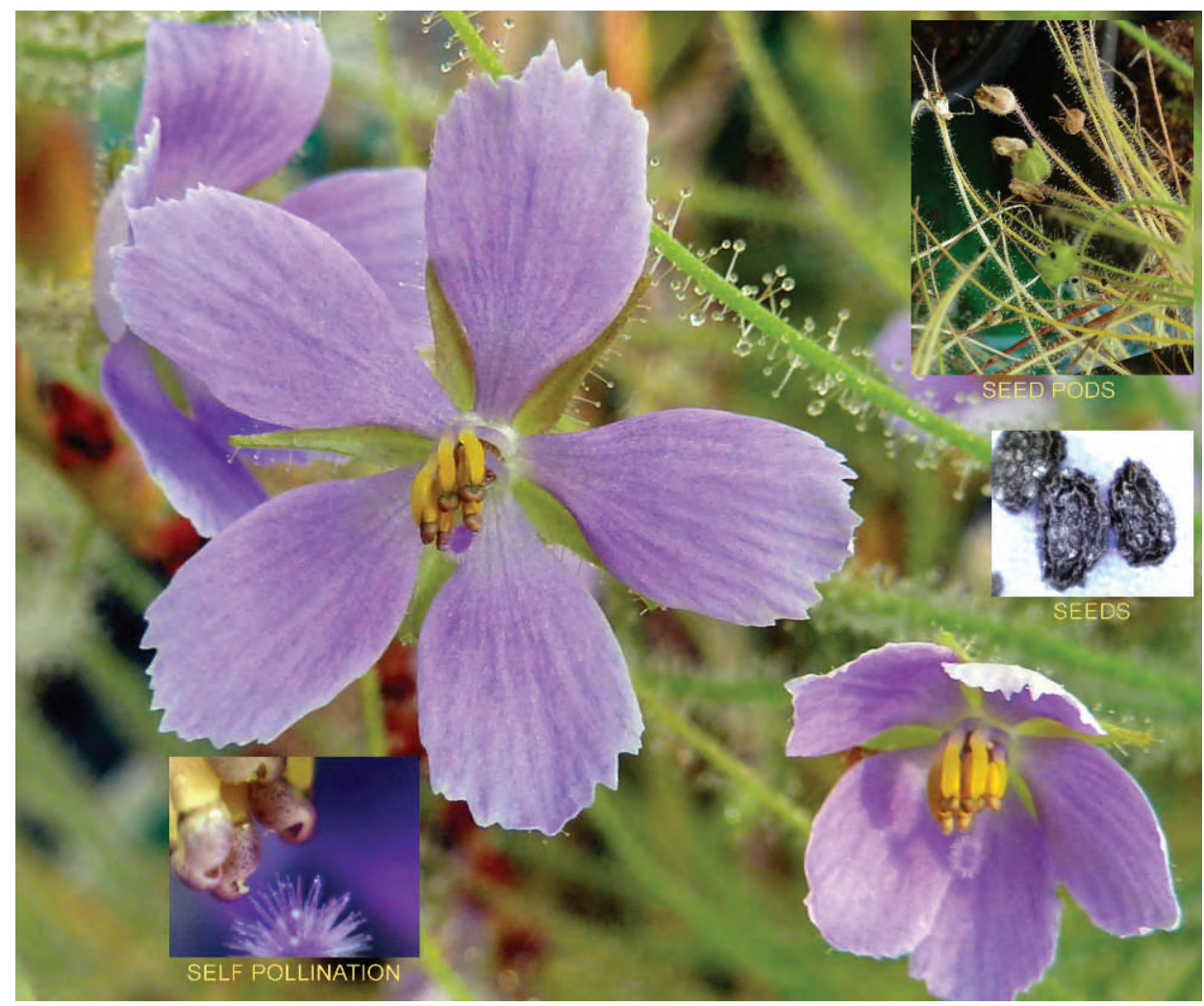

Figure 2: Byblis cf. filifolia $\times$ liniflora details. Photo by S. Hartmeyer.

For many years we have al so been growing a large B. filifolia from the Eastern $\mathrm{K}$ imberley region, which needs buzz-pollination to rel ease pollen. Holding the tip of an electrical tooth brush (without brush) close to the flower, while keeping a sheet of paper below, is a very easy and effective way to harvest pollen. However, a second and genetically different plant is necessary for successful pollination and seed production, as B. filifolia is self-sterile.

Byblis 'Goliath' is a robust cultivar of B. filifolia described by B rian Barnes (Barnes 2009, see Fig. 4).

In spring 2010, B rian Barnes asked us to grow and compare his cultivar Byblis 'Goliath' with plants grown from seeds labelled Byblis guehoi (ex CPUK seed bank), and to report the movement of leaves in the genus by pulvini which B rian found out and published first (Barnes 2009), on video. Sown in M arch 2010 after a treatment with $0.1 \%$ Gibberelinic acid for 24 hours, seeds of both plants germinated within 5- 7 days, which is actually fast. B oth plants grew with the same speed, branching strongly from the beginning and starting flowering after about 6-7 weeks. A II plants including the small B. liniflora possess pulvini for the movement of leaves and pedicels.

We grew about 10 plants from each seed pack, so the pollination of the self-fertile species was no problem. But only Byblis 'Goliath' produced healthy seed pods (pollen released with a tooth brush) during the whole season, the other plants from seeds labelled B. guehoi (ex CPUK seed bank) proved to be totally sterile. This was the only, but interesting difference we observed between the plants. Even the typical bright yellow anthers showed an identical single brown structure, which varies in number with different Byblis taxa and may even be totally absent. In our 


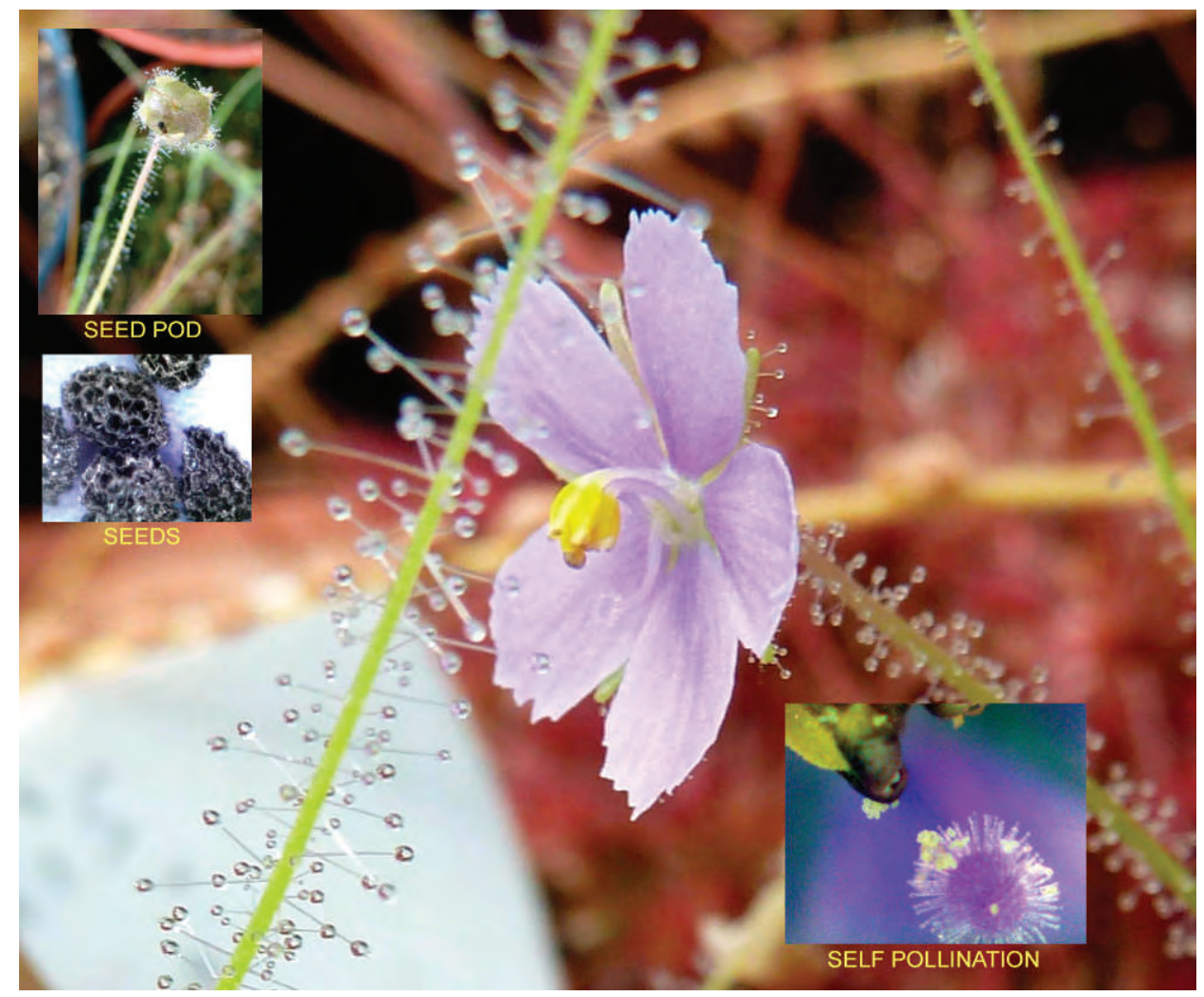

Figure 3: Byblis 'David' details. Photo by S. Hartmeyer.

opinion both plants appear to be very closely related, extremely branching varieties of $\mathrm{B}$. filifolia, one fertile and one infertile.

Considering possible cross-pollination that may result in partly fertile hybrids, it cannot be excluded with certainty that large and extreme branching plants like our Byblis 'Goliath' are indeed the result of former unnoticed hybridization in a greenhouse or even in nature.

In autumn 2010, we pollinated two Byblis 'Goliath' flowers, dipping a flower of Byblis 'David' on them. A pot with D rosera ultramafica was standing beneath the flowers. U nfortunately we missed the moment when the seed pods opened and were therefore happily surprised when we found (after our return from a USA CP-trip in M ay 2011) healthy seedlings growing in that pot with D. ultramafica. Five of seven plants developed homogenously very fast. Two plants remained small and unbranched unlike the large parent species. These could have been seedlings of selfed $B$. liniflora and were therefore not included in the measurements for Table 1.

While the growing shape appears like an airy form of Byblis 'Goliath', the flowers are selfpollinating, looking like those of the smaller Byblis 'David'. Self-pollination takes place in the afternoon and we were able to document that with our USB-microscope. A Imost every flower of these apparent F1-hybrids (see Fig. 5) automatically produced a seed pod containing lots of healthy seeds, which ripen fast and germinate without any treatment (GA 3, etc.) within only 7-9 days. Twenty one of these $\mathrm{F} 2$ generation plants thrive and are now 20-45 mm high. These F2 plants needed some more weeks to flower at the time of writing, but it will be very interesting to 


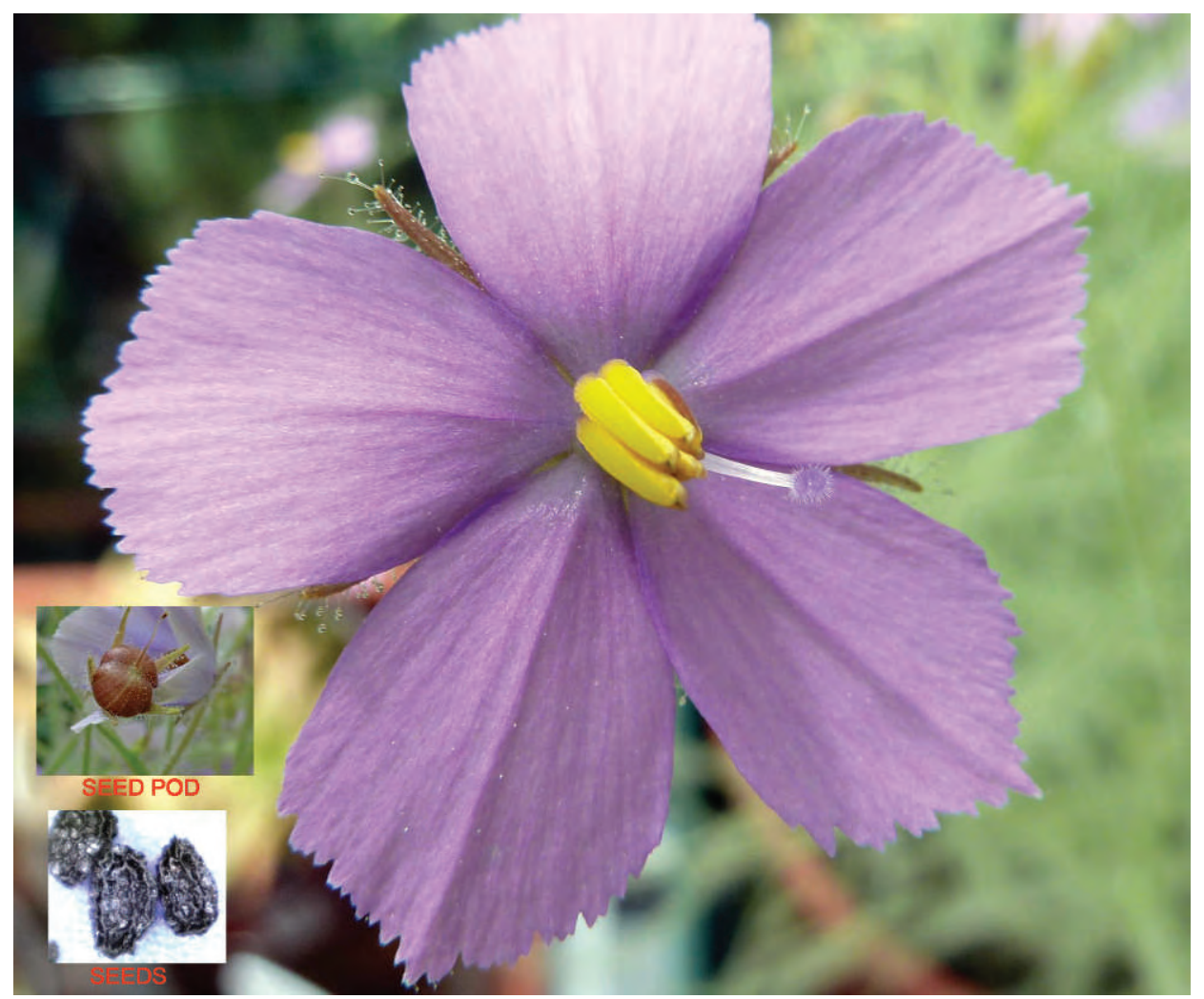

Figure 4: Byblis 'Goliath' details. Photo by S.Hartmeyer.

see what variation of growing shapes, pollination-type, branching and size of flowers and seed pods will appear.

To verify if the described hybridization is reproducible, we repeated the cross-pollination experiment at our greenhouse in early A ugust 2011, using this year's generation of Byblis 'David' and

\begin{tabular}{|l|c|c|c|}
\hline \multicolumn{4}{|l|}{ Table 1. Representative measurements of the supposed hybrid and its supposed parents. } \\
\hline Character & Byblis 'David' & Byblis cf. filifolia × liniflora & Byblis 'Goliath' \\
\hline Largest flowers* & $12-15 \mathrm{~mm}$ & $20 \mathrm{~mm}$ & $27 \mathrm{~mm}$ \\
\hline Seed pods & $4-5 \mathrm{~mm}$ & $5-6 \mathrm{~mm}$ & $10 \mathrm{~mm}$ \\
\hline L ongest leaves & $50 \mathrm{~mm}$ & $70 \mathrm{~mm}$ & $50-70 \mathrm{~mm} * *$ \\
\hline Pedicel & $45 \mathrm{~mm}$ & $55 \mathrm{~mm}$ & $60-95 \mathrm{~mm} * *$ \\
\hline Branching & $\mathrm{No}$ & $5-9$ & $>10$ \\
\hline
\end{tabular}

* Byblis 'Goliath' and Byblis cf. filifolia × liniflora al so partly produce clearly smaller flowers (while the flower size of B. liniflora is relatively constant), therefore we took only the size of the largest flowers for comparison.

** Our one-year-old B. 'Goliath' plant is still flowering, but now with mainly creeping branches, it usually develops only very short leaves (mainly approx. $40 \mathrm{~mm}$ ), much shorter than during the erect growth in the first 6 months. A Iso the pedicels are now mainly $60-70 \mathrm{~mm}$ long. 


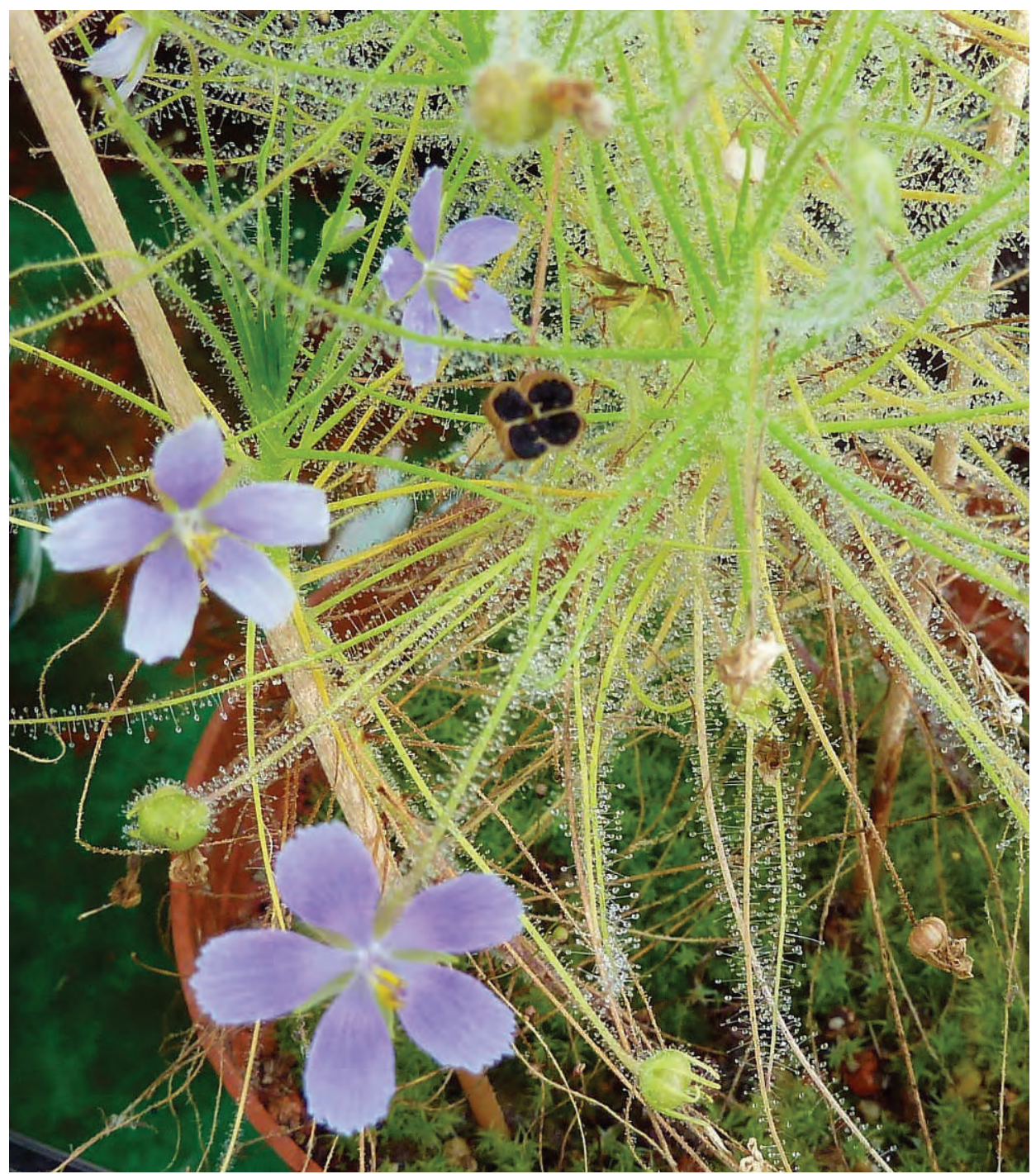

Figure 5: Byblis cf. filifolia $\times$ liniflora mature plant with maturing seedpods. Photo by S. Hartmeyer.

Byblis 'Goliath', grown from seeds of the P-generation (2010). Six days later the first pollinated flower showed a clearly swollen ovary and after 10 days a healthy developing seed pod was visible. A fter 20 days the seed pod opened at a size of $5 \mathrm{~mm}$ diameter, and released four healthy looking and three undersized seeds. A Iso a second of three cross-pollinated flowers showed a swollen ovary at the beginning, but withered after two weeks because the pedicel had been damaged bel ow the sepals, probably during pollination. This single (it was the only Byblis 'Goliath' plant in our collection in 2011) self-sterile plant never produced seed pods without being artificially pollinated either with a Byblis ' David' flower or with pollen of another Byblis 'Goliath' plant, harvested by the "electrical tooth brush method". 
The successful repetition of this cross-pollination verifies that interspecific hybrids can be produced artificially in the genus. Considering that meanwhile both parental cultivars exist in many $\mathrm{CP}$-collections and even nurseries, cross-pollination of the parent plants could be a very easy way to establish the showy self-pollinating hybrid in larger quantities in cultivation.

The supposed hybrid appears intermediate between its supposed parents B. 'Goliath' and B. 'D avid' and is self-pollinating and self-fertile. Table 1 shows a comparison of representative measurements of the five homogenously growing plants (excluded are two non-branching plants of uncertain parentage). The branching pattern is like the maternal B. 'Goliath' plant, the flowers look like those of B. 'David'.

\section{Discussion}

So far the only successful hybridization of Byblis has been reported by B rian Barnes in M arch 2008, crossing the cultivar Byblis 'G oliath' with Byblis rorida, while other authors stated that cross pollination in the genus has never been observed in the wild (A. Lowrie, ICPS Conference L eiden 2010). A $n$ internet search for Byblis hybrids shows only the mentioned report by $B$ rian $B$ arnes, and a failed experiment to cross B. gigantea with B. filifolia. Stewart $M$ cPherson reports ( $M$ cPherson 2010, page 972): "No naturally occurring Byblis hybrids have been recorded with certainty."

However, the successful interspecific cross pollination under greenhouse conditions should encourage field researchers to now look particularly for natural Byblis hybrids in tropical Australia, where different species are sympatric. If fertile hybrids occurred also in the wild, the identification of taxa could be complicated by back crossing, comparable to the situation in some taxa of Nepenthes and Sarracenia, where hybrids occur commonly in the field.

A cknowledgement: We thank B rian B arnes for the trustful provision of Byblis ' Goliath' seeds (Pgeneration) and personal communication such as his observations on pulvini in the genus, which enabled our time-lapse documentation on video as well as the experiments which finally led to the appearance of the supposed hybrid.

\section{References}

Barnes, B. 2009. Byblis 'G oliath', in New Cultivars. Carniv. PI. Newslett. 38: 16-18.

Barnes, B. 2010. Byblis 'D avid', in N ew Cultivars. Carniv. Pl. Newslett. 39: 43-44.

Hartmeyer, S., and Hartmeyer, I. 2010.

http://www.youtube.com/watch? $v=$ cE SW 11j6SrM

http://www.youtube.com/watch?v=B O pnFaxC-hE

M cPherson, S. 2010. Carnivorous Plants and their Habitats, vol. 2. Dorset: Redfern N atural History Prod. 